\title{
Survival in advanced GIST has improved over time and correlates with increased access to post-imatinib tyrosine kinase inhibitors: results from Life Raft Group Registry
}

\author{
Jerry W. Call ${ }^{1 *} \mathbb{D}$, Yu Wang ${ }^{1}$, Denisse Montoya ${ }^{1}$, Norman J. Scherzer ${ }^{1}$ and Michael C. Heinrich ${ }^{2}$
}

\begin{abstract}
Background: The use of imatinib, sunitinib, and regorafenib has transformed the treatment of advanced GIST. Sunitinib and regorafenib improve progression free-survival in the second (2L) and third (3L) line, respectively, compared with placebo. However, the impact of these agents on overall survival (OS) is unclear.

Methods: The Life Raft Group (LRG) patient registry contains records from 1716 GIST patients; 526 have advanced to at least $2 \mathrm{~L}$ treatment. Patient-reported treatment and outcome data were examined to determine treatment patterns and their impact on OS.

Results: Median OS from start of $2 \mathrm{~L}$ therapy was 32.4 months for sunitinib $(n=436)$ compared with 27.1 months for patients treated with any other $2 \mathrm{~L}$ drug $(n=74, p=0.023, \mathrm{HR} 1.377)$ and 16.8 months for patients who never received sunitinib in any treatment line $(n=42, p=0.028, H R 1.52)$. In patients reporting progression in $2 \mathrm{~L}$, the median OS in patients subsequently receiving $3 \mathrm{~L}$ regorafenib ( $n=53,26.2$ months) was longer than that of $3 \mathrm{~L}$ patients who never received regorafenib in any line of therapy $(n=174,14.3$ months, $p=0.0002, H R 2.231)$, and was longer than that of patients who received any other $3 \mathrm{~L}$ treatment (19.8 months, $p=0.044$, HR 1.525). OS for advanced GIST patients in the LRG registry has improved over time $(p=0.0013)$, correlated with the increased use of TKIs in $\geq 2 L$ settings.

Conclusions: In our analysis, sunitinib and regorafenib significantly improved OS compared with patients who never received these agents. Our data also support the hypothesis that the use of KIT/PDGFRA inhibitors, including nonapproved agents, has improved OS for patients with imatinib- and sunitinib-resistant GIST.
\end{abstract}

Keywords: Gastrointestinal stromal tumors, GIST, Regorafenib, Sunitinib, Survival

\section{Background}

Gastrointestinal stromal tumors are soft tissue sarcomas that arise from interstitial cells of Cajal (ICC) or from stem cells that can differentiate towards ICCs. GIST have a reported incidence of approximately 14.5 per million per year [1]. Primary tumors most commonly originate in the stomach or intestines and frequently metastasize to the liver or the peritoneum $[2,3]$.

*Correspondence: jcall@liferaftgroup.org

1 Life Raft Group, 155 Route 46 West, Suite 202, Wayne, NJ 07470, USA

Full list of author information is available at the end of the article
Following successful clinical studies of imatinib which began in $2000[4,5]$, treatment with tyrosine kinase inhibitors (TKIs) became the standard treatment for advanced GIST. TKI's currently approved for GIST in the United States and many other countries include imatinib [6], sunitinib [7] and regorafenib [8]. Imatinib is approved for first line (1L) therapy for advanced/metastatic GIST and for adjuvant treatment after surgery. Sunitinib is approved after progression on or intolerance to imatinib [7]. Regorafenib is approved for patients previously treated with imatinib and sunitinib $[8,9]$.

Approximately 75 to $80 \%$ of GISTs have activating mutations in KIT and another 5-8\% harbor mutations in 
PDGFRA [10]. These mutations are felt to be the pathogenic event that initiates tumor formation [11]. TKIs that inhibit the signaling from these mutated proteins are the primary drug treatment for GISTs. The most common cause of GIST resistance to imatinib, and other TKIs, is secondary mutations in the driver mutant kinase [12]. In $K I T$, these secondary mutations most commonly occur in exons 13, 14, 17 and 18 [12, 13]. The ability of sunitinib and regorafenib to inhibit, at least some, of these secondary mutations provides the likely basis for their antitumor activity in imatinib-resistant GIST patients $[13,14]$.

The reported survival times for GIST patients vary widely depending on stage of disease [15], the era reported [16-18] and the landmark used for measuring survival. The extent of improved survival due to individual lines of TKI therapy is unclear. For example, the early imatinib metastatic studies were enriched for patients with bulky disease [4]. Survival in those studies may have been shorter than for metastatic disease patients diagnosed currently with less advanced/bulky disease. Imatinib improves survival when given as adjuvant treatment [19] and the current paradigm of surveillance during and after adjuvant therapy likely leads to the earlier detection of recurrent disease. In addition, the OS reported for the early imatinib studies may not fully capture the additional survival benefits due to use of salvage sunitinib and regorafenib. While sunitinib was initially reported to increase OS compared to placebo [20], the phase 3 study design which allowed crossover from placebo to active drug upon progression, has obscured the actual survival benefit of this agent [20]. The survival benefit of regorafenib is also unclear [21]. Notably, in the phase 3 regorafenib vs. placebo study (GRID), the OS benefit of regorafenib was not identified at the time the results were published in 2012 [21] potentially due to the high rate of cross-over from placebo to regorafenib. Therefore, the impact of $2 \mathrm{~L}$ sunitinib and $3 \mathrm{~L}$ regorafenib on the OS of advanced GIST patients remains unclear.

Sunitinib entered clinical testing in 2002 and was FDA approved for 2L treatment of GIST in 2006 [7]. In the phase III trial that resulted in sunitinib regulatory approval, the median time to tumor progression was 6.3 months for sunitinib and 1.5 months for placebo [20]. At the initial publication of trial results, the median OS for those on sunitinib had not been reached but was superior to the placebo group (HR 0.49, 95\% CI 0.29$0.83, p=0.007)$. In a later analysis, the median OS for the sunitinib arm of this trial was 16.7 months [22]. However, the survival difference between the sunitinib arm and the placebo was no longer significant ( $p=0.306$, HR 0.876 ).

Regorafenib entered phase II testing for GIST in 2010 [23, 24] and phase III studies in 2011 [21], and received FDA approval for IM/SU-resistant GIST in 2013 [8].
Here, we used real-world evidence from patient-reported outcomes to analyze the clinical benefit of $2 \mathrm{~L}$ sunitinib and $3 \mathrm{~L}$ regorafenib treatment in advanced GIST OS.

\section{Methods \\ Patient selection}

The Life Raft Group Registry started in 2000 and currently includes over 1700 GIST patients (Fig. 1). The Life Raft Group (https://liferaftgroup.org) is an international, internet-based private, non-profit medical research and patient advocacy organization. This is a retrospective analysis of a long-term observational study of those patients.

\section{Study design and statistical methods}

In this article, we report on OS and self-reported progression-free survival (srPFS) of patients in the registry, with a focus on $2 \mathrm{~L}$ and $3 \mathrm{~L}$ treatments (Fig. $2 \mathrm{a}-\mathrm{C}$ ). OS and srPFS estimates were determined using the KaplanMeier method and the log-rank test (Figs. 3, 4, 5, 6), or the Gehan-Breslow-Wilcoxon test (Fig. 4). The $p$-values $<0.05$ were considered significant. Statistical data analyses were performed using $\mathrm{R}$ version 3.5.1 ( $\mathrm{R}$ Foundation, Vienna, Austria, https://www.R-project.org/). The multi-variable analysis of factors associated with post-2L treatment OS was conducted by Cox regression in IBM SPSS Statistics 25. For the cohort with a variable proportional hazard, we used the Fleming-Harrington weighted log-rank test. The pair-pair variable correlation was analyzed by Spearman correlation coefficiency analysis followed by post hoc Bonferroni correction. For the 3L analysis of the effect of expanded TKI usage over time, patients that reached $3 \mathrm{~L}$ were divided into three groups based on the year they started 3L treatment (2002-2006, 2007-2012 and 2013+). These categories were selected to coincide with the evolving use of $3 \mathrm{~L}$ treatments, influenced by approval of new TKIs.

\section{Treatment lines}

Imatinib is the established first line treatment for GIST [9] and was given for $>98 \%$ of $1 \mathrm{~L}$ treatments in the registry. Patient Characteristics are described in Additional file 1: Table S1. The data cutoff date for this study was April 7th, 2017 (Fig. 1). At that time, there were 1716 patients in the registry and 633 were deceased (37\%). There are 3249 drug treatments recorded in the registry and 3122 of these were included in our analysis. Excluded treatment records include traditional chemotherapy (often before the TKI era) treatments for a second cancer, known placebo treatments, and instances of intolerance to treatment (defined as discontinuation within 1 month due to side effects). Other than listing the frequency of various first-line treatments, no further analysis of first line treatment is included. Patient characteristics for $3 \mathrm{~L}$ 


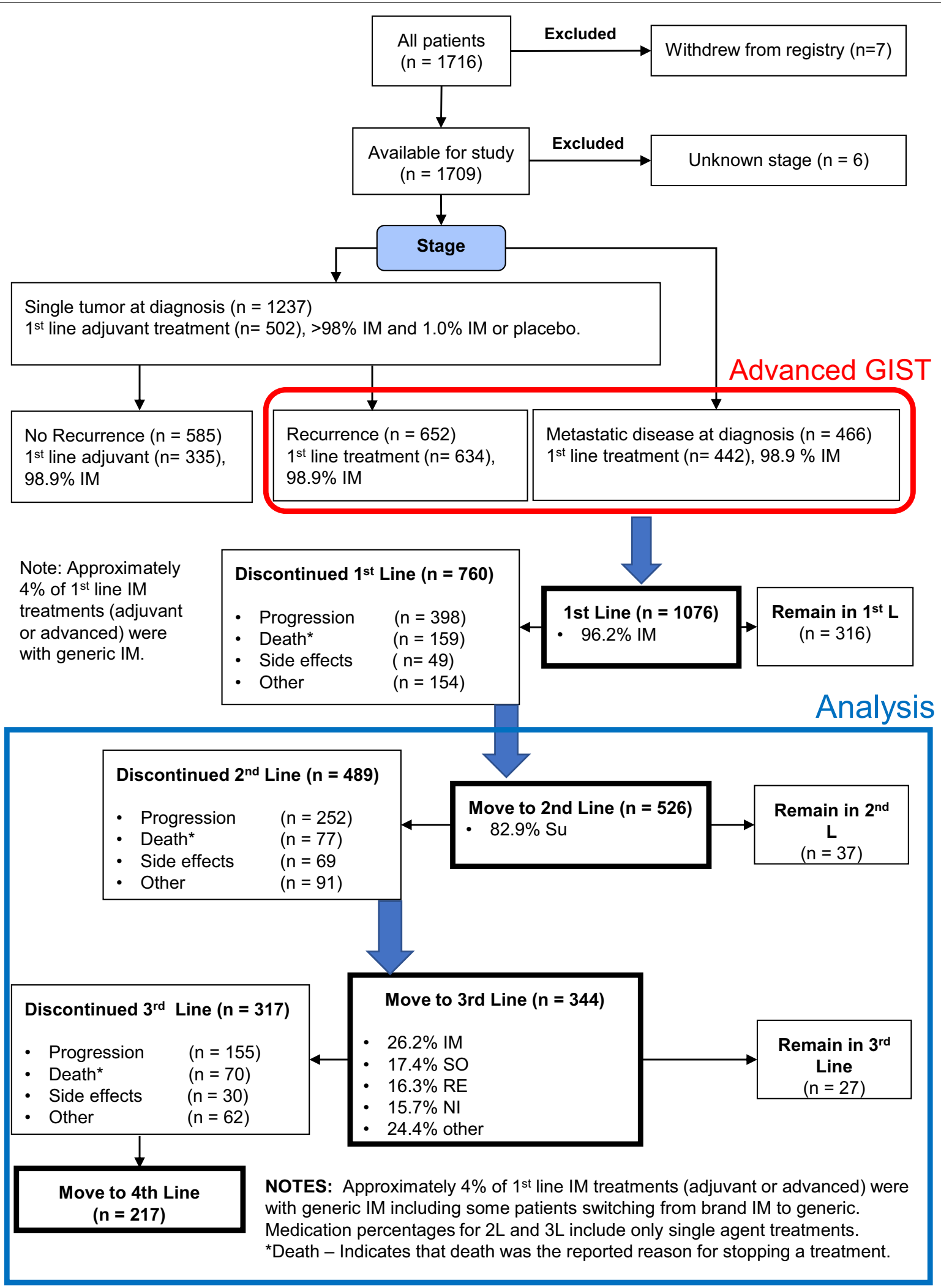

Fig. 1 Flowsheet of outcomes as reported by patients 

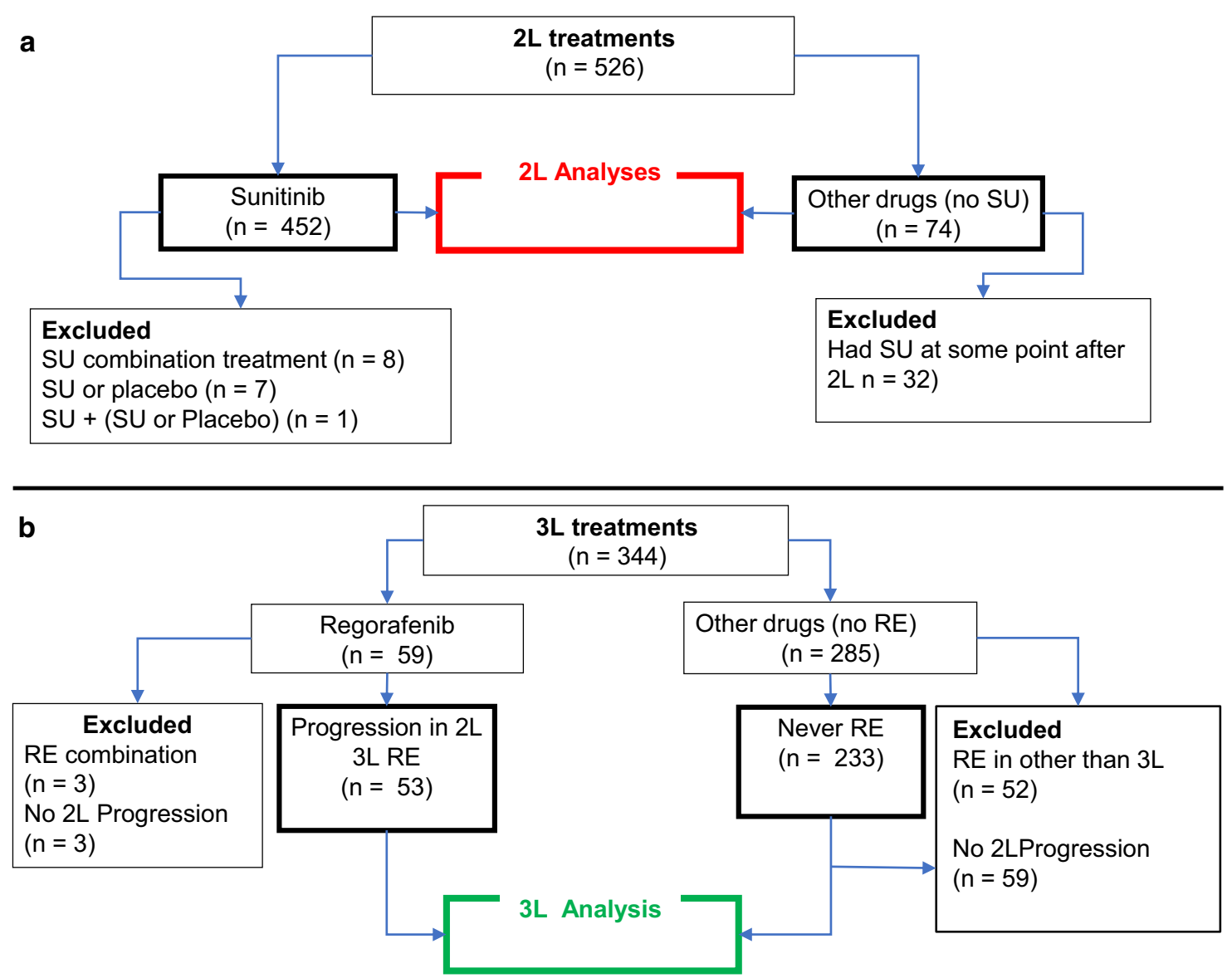

c

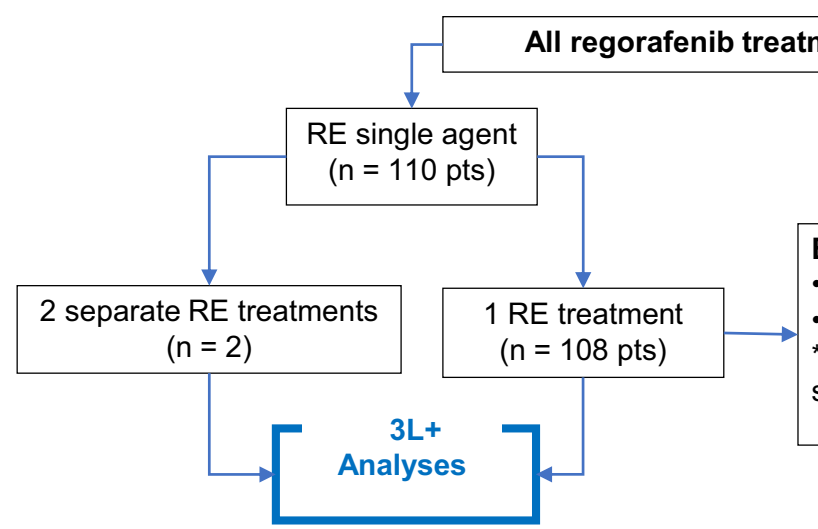

Fig. $22 L, 3 L$ and $3 L+$ comparison groups

treatment (which was much more heterogeneous than $2 \mathrm{~L}$ treatment) is described in Table 1.

The number of patients in each treatment line is described in Additional file 1: Table S2 and single agent regorafenib use in any treatment line is described in Additional file 1: Table S3.
Patient-reported evaluations and progression

Evaluations including CT scans (84\%), MRI's (6\%), PET scans $(8 \%)$ and ultrasounds $(1 \%)$ are reported to the registry. Patients have fixed choices to describe the results including (this example is for CT scans), NED, Shrink, Stable, Growth, Mixed and New Tumors. Registrar's 


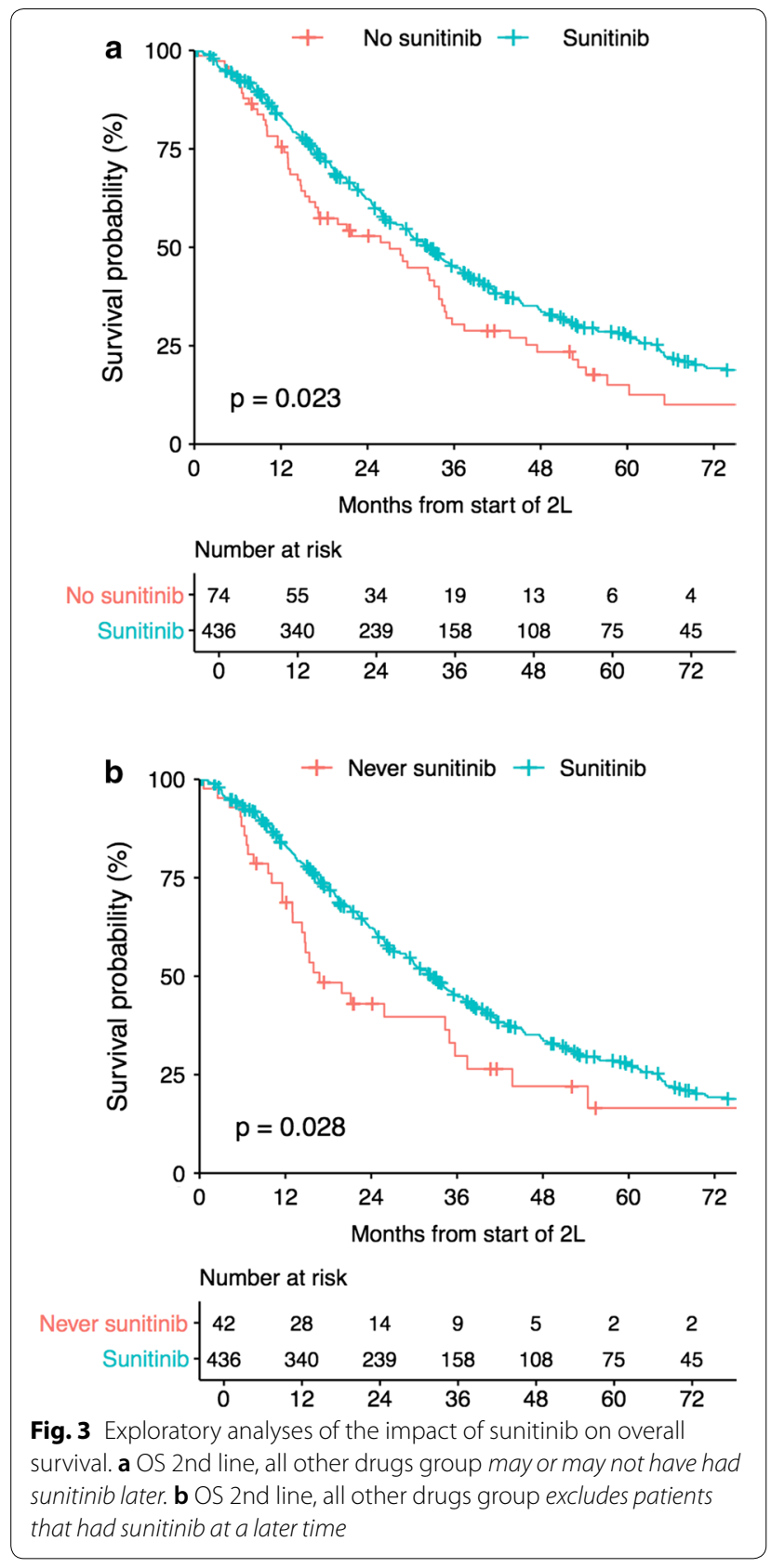

review the results and, in cases of suspected or verified progression, mark the record as progression. In addition, patients can report progression as a reason for changing dose or stopping drug. If progression is recorded in either evaluations or as a reason for stopping/changing drug dose, then the earliest date of progression is recorded and used in srPFS calculations. Radiology reports can be submitted by patients, but most patients do not submit the actual reports. Comments can also be provided by the patients (and are often detailed) in both evaluations and the medication details records.
Patient-reported surgeries within $2 \mathrm{~L}$ and $3 \mathrm{~L}$ treatment periods

Our goal was to evaluate potential benefit of surgery related to $2 \mathrm{~L}$ and $3 \mathrm{~L}$ treatment. Since surgery sometimes occurs near a change in treatment, we considered benefit from surgeries occurring just before a treatment change to be most related to the subsequent treatment. As a result, we considered surgery to be within $2 \mathrm{~L}$ (or $3 \mathrm{~L}$ respectively) if surgery was done within the period starting 30 days prior to the start of the treatment line and ending 30 prior to the end of the treatment line.

\section{Results}

Sunitinib as $2 \mathrm{~L}$ treatment improved patient $\mathrm{OS}$

In the LRG registry, a total of 526 patients received $2 \mathrm{~L}$ treatment, and 436 patients $(82.9 \%)$ were treated with single-agent sunitinib $(84.6 \%$ if sunitinib combination treatments are also counted). For the 436 patients who received single-agent sunitinib as $2 \mathrm{~L}$ treatment, the median OS from the start of $2 \mathrm{~L}$ treatment was 32.4 months and the median srPFS was 8.4 months. For the entire group of patients $(n=526)$ receiving $2 \mathrm{~L}$ treatments the median OS was 30.3 months.

We performed several exploratory analyses of survival benefit for sunitinib used as $2 \mathrm{~L}$ treatment. However, because selection bias may play a role in the makeup of the comparison groups, the results should be interpreted with caution.

We compared patients that received sunitinib with patients that received another drug as $2 \mathrm{~L}$ (Fig. 3a). The median OS of the sunitinib group $(n=436)$ was 32.4 vs. 27.1 months for the alternative $2 \mathrm{~L}$ treatment group $(\mathrm{n}=74, p=0.023$, HR 1.377, 95 CI 1.044-1.816). We also compared patients that received sunitinib versus patients that never received sunitinib at any time (Fig. 3b). The median OS of the sunitinib group $(n=436)$ was 32.4 months vs. 16.8 months for the never received sunitinib group $(\mathrm{n}=42, p=0.028, \mathrm{HR} 1.52,95 \mathrm{CI} 1.044$ to 2.19). The median OS from the start of $2 \mathrm{~L}$ sunitinib was noted to increase over time (Fig. 4). Patients that started $2 \mathrm{~L}$ treatment in the time frame the sunitinib studies were recruiting (<2006), had a median OS of 22.1 months. For patients starting $2 \mathrm{~L}$ treatment from 2006 to 2016, the median OS was 34.9 months $(p=0.0015)$.

\section{Factors affecting $2 \mathrm{~L} O S$}

Using a Cox regression model, we investigated variables affecting $2 \mathrm{~L}$ OS. The year $2 \mathrm{~L}$ treatment was started was significant $(p=0.029$, HR 0.9607) until the use of regorafenib (all except 2 regorafenib treatments were post $2 \mathrm{~L}$ ) was added to the model causing $2 \mathrm{~L}$ start year to lose significance $(p=0.688)$. In the second model, variables found to be significant were: patient ever had 

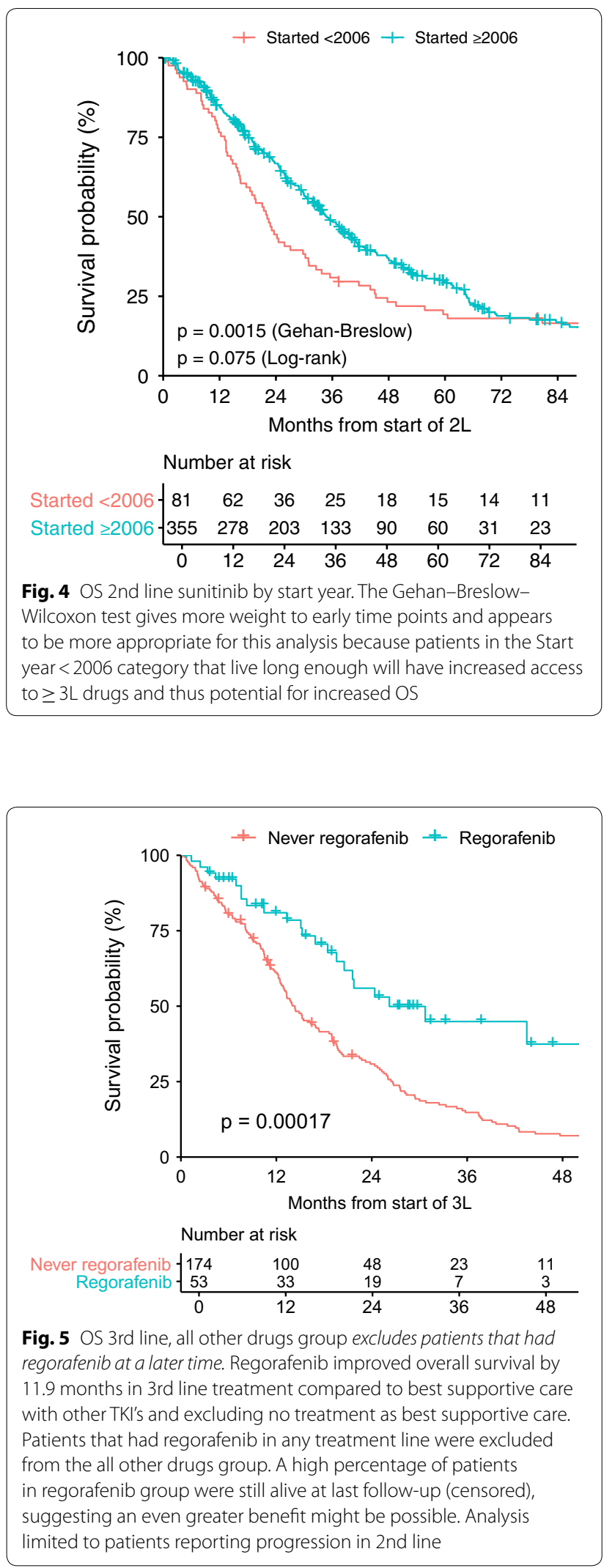

regorafenib $(p<0.00001, \mathrm{HR} 0.4754)$, patient reported progression in $1 \mathrm{~L}(p=0.0008, \mathrm{HR} 1.7121$, favoring those not reporting progression in $1 \mathrm{~L}$ ), patient ever had sunitinib ( $p=0.022$, HR 0.6477), patient reported knowing their mutation $(p=0.0001$, HR 0.6522 , favoring the patients that knew their mutation), gender ( $p=0.0004$, HR 1.4658, favoring females) and age at start of treatment $(\mathrm{p}<0.00001, \mathrm{HR} 1.0203$ per year).

In the third and final model (Additional file 1: Table S4), when patients knowing or not knowing their mutation was replaced with the actual mutation (but still including unknown mutation as a group) only two groups were significantly different than patients with KIT 11 mutations (the reference mutation). Patients with no mutation in KIT or PDGFRA (KIT/PDGFRA WT) had longer $2 \mathrm{~L}$ OS $(\mathrm{p}=0.0048 \mathrm{HR} 0.4830)$, and patients reporting as unknown mutation had shorter $2 \mathrm{~L}$ OS ( $p=0.037 \mathrm{HR} 1.3194)$. Of the $12 \mathrm{D} 842 \mathrm{~V} 2 \mathrm{~L}$ patients, 9 had treatment at some time (not necessarily in $2 \mathrm{~L}$ ) with one of four agents with suspected activity against D842V mutations, dasatinib [25] ( $\mathrm{n}=5 \mathrm{pts})$, crenolanib [26] ( $\mathrm{n}=5 \mathrm{pts})$, avapritinib [27] (BLU-285, $\mathrm{n}=3$ ) or olaratumab [28] $(\mathrm{n}=2)$. Although the hazard ratio of 0.5799 for D842V patients compared to KIT exon 11 patients was relatively low, the difference in $2 \mathrm{~L}$ OS was not significant, $p=0.1691$, however in multi-variable analysis it was significant in $3 \mathrm{~L}$, provided start year was used as a variable instead of start year category $(p=0.024$ HR 0.3484$)$. The small number of D842Vdirected treatments spread across different treatment lines limits the efficacy analysis of any specific treatment for patients with the D $842 \mathrm{~V}$ mutation. In addition, the trajectory of the disease seems to have more interpatient variability in the KIT/PDGFRA WT and $\mathrm{D} 842 \mathrm{~V}$ groups, with some of these patients having a more indolent course. In the KIT/PDGFRA WT group this is likely due to a high percentage of undiagnosed SDH-deficient patients within the group and their known potential for an often indolent nature [29]. This interpatient variability combined with small numbers of patients and the limitations of the median as a sole outcome measure (especially with small numbers) can sometimes lead to counterinitiative results. For example, in this series with 3 patients failing to transition from $2 \mathrm{~L}$ to $3 \mathrm{~L}$, the $3 \mathrm{~L} \mathrm{D} 842 \mathrm{~V}$ patients $(\mathrm{n}=9$, median OS 61.7 months), had longer OS than $2 \mathrm{~L}$ D $842 \mathrm{~V}$ patients ( $\mathrm{n}=12$, median OS 34.4 months).

\section{Regorafenib treatment improves OS}

In the LRG registry, 114 patients received regorafenib in 117 separate treatments ( 3 pts received two separate 


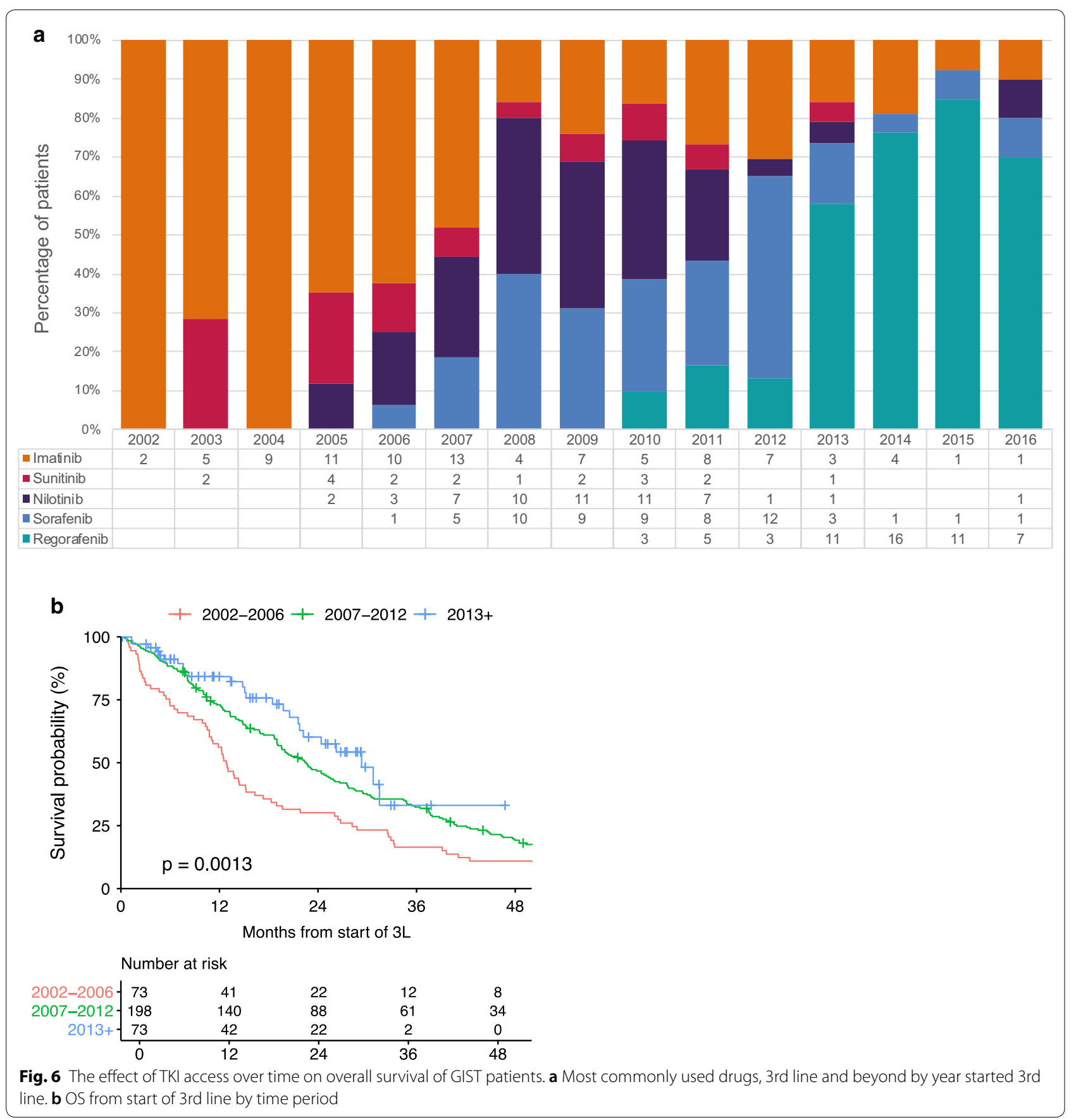

treatments each with regorafenib and one of these 6 treatments was a combination treatment). One hundred and seven patients receiving 109 separate treatments are included in the $3 \mathrm{~L}+$ analyses. See Additional file 1: Table S3 for regorafenib usage by treatment line.

Fifty-six of these patients received single-agent treatment in the $3 \mathrm{~L}$, matching the current approved indication; three additional patients received regorafenib in combination with embolization in 3L for a total of 59 $3 \mathrm{~L}$ treatments. The three regorafenib combination treatments were excluded from analysis.

In the 3L, 53/56 (94.7\%) patients on regorafenib reported progression in $2 \mathrm{~L}$. In addition, 285 patients received a drug other than regorafenib for $3 \mathrm{~L}$ treatment and 233 of these patients never received regorafenib at any time. Further analysis was restricted to those that 
Table 1 Patient characteristics-3rd line treatment

\begin{tabular}{|c|c|c|c|c|}
\hline Year started 3rd line & $2002-2006$ & $2007-2012$ & $2013+$ & Total \\
\hline Number of patients & 73 & 198 & 73 & 344 \\
\hline Alive & $3(4.1 \%)$ & $27(13.6 \%)$ & $48(65.8 \%)$ & $78(22.7 \%)$ \\
\hline Dead & $70(95.9 \%)$ & $171(86.4 \%)$ & $25(34.2 \%)$ & $266(77.3 \%)$ \\
\hline Had regorafenib at any time & $2(2.7 \%)$ & $48(24.2 \%)$ & $61(83.6 \%)$ & $111(32.3 \%)$ \\
\hline Female & $31(42.5 \%)$ & 77 (38.9\%) & $39(53.4 \%)$ & $147(42.7 \%)$ \\
\hline Male & $42(57.5 \%)$ & $121(61.1 \%)$ & $34(46.6 \%)$ & $197(57.3 \%)$ \\
\hline Median age/range at start of treatment (3L) & $54.0(18-90)$ & $58.2(18-88)$ & $60.8(19-84)$ & $57.8(18-90)$ \\
\hline \multicolumn{5}{|l|}{ Age at diagnosis } \\
\hline$<18$ & $3(4.1 \%)$ & $3(1.5 \%)$ & $2(2.7 \%)$ & $8(2.3 \%)$ \\
\hline$\geq 18-35$ & $9(12.3 \%)$ & $21(10.6 \%)$ & $6(8.2 \%)$ & $36(10.5 \%)$ \\
\hline$\geq 35$ & $60(82.2 \%)$ & $174(87.9 \%)$ & $65(89.0 \%)$ & $299(86.9 \%)$ \\
\hline Unknown & $1(1.4 \%)$ & - & - & \\
\hline \multicolumn{5}{|l|}{ Last reported treatment line } \\
\hline $3 \mathrm{~L}$ & $35(47.9 \%)$ & $57(28.8 \%)$ & 39 (53.4\%) & $131(38.1 \%)$ \\
\hline $4 \mathrm{~L}$ & $14(19.2 \%)$ & $37(18.7 \%)$ & $17(23.3 \%)$ & $68(19.8 \%)$ \\
\hline $5 \mathrm{~L}$ & $11(15.1 \%)$ & $32(16.2 \%)$ & $9(12.3 \%)$ & $52(15.1 \%)$ \\
\hline $6 \mathrm{~L}$ & $6(8.2 \%)$ & $32(16.2 \%)$ & $3(4.1 \%)$ & $41(11.9 \%)$ \\
\hline $7 \mathrm{~L}$ & $5(6.8 \%)$ & $19(9.6 \%)$ & $4(5.8 \%)$ & $28(8.1 \%)$ \\
\hline $8 \mathrm{~L}$ & 0 & $6(3.0 \%)$ & 0 & $6(11.9 \%)$ \\
\hline $9 \mathrm{~L}$ & $2(2.7 \%)$ & $8(4.0 \%)$ & $1(1.4 \%)$ & $11(3.2 \%)$ \\
\hline $10 \mathrm{~L}$ & 0 & $1(0.5 \%)$ & 0 & $1(0.3 \%)$ \\
\hline $11 \mathrm{~L}$ & 0 & $3(1.5 \%)$ & 0 & $3(0.9 \%)$ \\
\hline $12 \mathrm{~L}$ & 0 & $2(1.0 \%)$ & 0 & $2(0.6 \%)$ \\
\hline $13 \mathrm{~L}$ & 0 & $1(0.5 \%)$ & 0 & $1(0.3 \%)$ \\
\hline \multicolumn{5}{|l|}{ Mutations/\% (known mutations) } \\
\hline $\mathrm{KIT}$ & 15 (78.9\%) & 95 (75.4\%) & $40(75.5 \%)$ & $150(75.8 \%)$ \\
\hline Exon 11 & $10(52.5 \%)$ & $64(50.8 \%)$ & $31(58.5 \%)$ & $105(53.0 \%)$ \\
\hline Exon 9 & $5(26.3 \%)$ & $25(19.8 \%)$ & $7(13.2 \%)$ & $37(18.7 \%)$ \\
\hline Exon 13 & - & $4(3.2 \%)$ & $1(1.9 \%)$ & $5(2.5 \%)$ \\
\hline Exon 17 & - & $1(0.8 \%)$ & $1(1.9 \%)$ & $2(1.0 \%)$ \\
\hline PDGFRA & $1(5.3 \%)$ & $7(5.6 \%$ & $4(7.5 \%)$ & $12(6.1 \%)$ \\
\hline Exon 12 & & $1(0.8 \%)$ & - & $1(0.5 \%)$ \\
\hline Exon 18-D842V & $1(5.3 \%)$ & $5(4.0 \%)$ & $3(5.6 \%)$ & $9(4.5 \%)$ \\
\hline Exon 18 non-D842V & & $1(0.8 \%)$ & $1(1.9 \%)$ & $2(1.0 \%)$ \\
\hline Wildtype for KIT/PDGFRA & $3(15.8 \%)$ & $22(17.5 \%)$ & $7(13.2 \%)$ & $32(16.2 \%)$ \\
\hline SDHA & - & & $2(3.8 \%)$ & $2(1.0 \%)$ \\
\hline SDHB & - & $2(1.6 \%)$ & - & $2(1.0 \%)$ \\
\hline Total/\% known mutations & $19(26 \%)$ & $126(63.6 \%)$ & $53(72.6 \%)$ & $198(57.6 \%)$ \\
\hline Unknown mutations & $54(74.0 \%)$ & $72(36.4 \%)$ & $20(27.4 \%)$ & $146(42.4 \%)$ \\
\hline \multicolumn{5}{|l|}{ Primary tumor location } \\
\hline Small intestine & $32(43.8 \%)$ & 85 (42.9\%) & $34(46.6)$ & $151(43.9 \%$ \\
\hline Stomach & $27(37.0 \%)$ & 81 (40.9\%) & $29(39.7 \%)$ & 137 (39.8\%) \\
\hline Unknown & $7(9.6 \%)$ & $10(5.1 \%)$ & $2(2.7 \%)$ & $19(5.5 \%)$ \\
\hline Peritoneum & $1(1.4 \%)$ & $2(1.0 \%)$ & $3(4.1 \%)$ & $6(1.7 \%)$ \\
\hline Omentum & $1(1.4 \%)$ & $3(1.5 \%)$ & $1(1.4 \%)$ & $5(1.5 \%)$ \\
\hline Mesentery & $1(1.4 \%)$ & $4(2.0 \%)$ & - & $5(1.5 \%)$ \\
\hline Rectum/anus & $1(1.4 \%)$ & $3(1.5 \%)$ & $1(1.4 \%)$ & $5(1.5 \%)$ \\
\hline Colon & - & $5(2.5 \%)$ & - & $5(1.5 \%)$ \\
\hline Other & $3(4.1 \%)$ & $5(2.5 \%)$ & $3(4.1 \%)$ & $11(3.2 \%)$ \\
\hline
\end{tabular}


never received regorafenib in any line of therapy. Comparing these two groups, the median OS was 26.2 months for the regorafenib group and 15.2 months for the never received regorafenib group $(p=0.0027)$. In the 233 patients treated with a drug other than regorafenib who never received regorafenib in any line of treatment, 174 (74.7\%) of 233 reported progression in 2L. Due to this imbalance compared to those that received regorafenib $3 \mathrm{~L}$, we restricted further analyses to patients that reported progression in $2 \mathrm{~L}$.

For $3 \mathrm{~L}$ treatment of patients reporting progression in $2 L, 53$ received regorafenib and 174 never received regorafenib. Between these groups, regorafenib treatment compared with never receiving regorafenib was associated with improvement in OS by 11.9 months (26.2 months vs. 14.3 months, respectively, $p=0.0002$, HR 2.231, CI 1.45-3.43) (Fig. 5). The most common drugs used in $3 \mathrm{~L}$ in the no regorafenib/progressed in $2 \mathrm{~L}$ group were imatinib $(\mathrm{n}=50,28.9 \%)$, nilotinib $(\mathrm{n}=37$, $21.4 \%)$, sorafenib $(\mathrm{n}=36,20.8 \%)$ and sunitinib $(\mathrm{n}=10$, $5.8 \%$ ). The use of sorafenib and nilotinib was likely influenced by ongoing phase $2-3$ studies of these agents prior to the approval of regorafenib [30-33].

One hundred and seven LRG registry patients received 109 treatments with regorafenib monotherapy beyond $2 \mathrm{~L}$ (two patients received regorafenib in two separate treatment lines). The median OS of these patients was 22.5 months and the median srPFS was 7.2 months (Table 2). Fifty-six (51.4\%) of these patients received regorafenib $3 \mathrm{~L}$ and 53 (48.6\%) received regorafenib after 3L. These numbers are similar to the GRID study (Table 2), where $44 \%$ received regorafenib after 3L [21]. In that study, 133 patients in the regorafenib arm had an OS of 17.4 months [22] and PFS of 4.8 months [21], however, investigator-assessed median PFS was 7.4 months.

\section{The effect of continued TKI access in patients in the pre-regorafenib era and into the regorafenib era}

Third line treatment in the LRG registry was much more varied than $1 \mathrm{~L}$ or $2 \mathrm{~L}$ and was highly correlated with the time period at the start of $3 \mathrm{~L}$ therapy (Fig. 6a and Additional file 1: Table S5). The participation in clinical studies of sunitinib and regorafenib, the approval of sunitinib for $2 \mathrm{~L}$ in 2006, regorafenib for 3L in 2013 and the availability of nilotinib and sorafenib starting in $~ 2007$ (either off-label or in phase 2-3 studies) influenced treatment patterns for advanced GIST (Fig. 6a). From 2002 through 2006 , treatment with imatinib dominated $3 \mathrm{~L}$ and $3 \mathrm{~L}+$ treatments. 2007 was a transition year between imatinib use and subsequent higher rates of nilotinib or sorafenib usage. This trend continued in 2008 with high usage of either nilotinib or sorafenib, and some continued use of imatinib or sunitinib in later treatment lines. In 2012,
Table 2 LRG registry $3 L+$ regorafenib use compared to GRID trial

\begin{tabular}{lllll}
\hline & $\begin{array}{l}\text { No. of Pts/ } \\
\text { treatments }\end{array}$ & $>$ 3rd line \% & $\begin{array}{l}\text { Median OS } \\
\text { (months) }\end{array}$ & $\begin{array}{l}\text { Median } \\
\text { PFS/srPFS } \\
\text { (months) }\end{array}$ \\
\hline $\begin{array}{l}\text { Phase III } \\
\text { GRID Trial } \\
\text { (regorafenib } \\
\begin{array}{l}\text { arm only) } \\
\text { LRG Registry } \\
\text { 3L+ }\end{array}\end{array}$ 107/109 & 44 & $17.4^{32}$ & $4.8^{\mathrm{a}}$ \\
\hline
\end{tabular}

a 7.4 investigator assessment

b Two patients received two separate treatments of regorafenib beyond $2 \mathrm{~L}$ for a total of 109 separate treatments beyond $2 \mathrm{~L}$. Four other patients received regorafenib $2 \mathrm{~L}$ for a total of 113 treatments with single-agent regorafenib in the registry. Two of the $2 \mathrm{~L}$ patients were intolerant to regorafenib. Four other patients received regorafenib in combination with another treatment. A total of 114 patients received 117 treatments with regorafenib when all treatment lines, single agent and combinations were included

use of nilotinib dropped while sorafenib use remained common through 2012, dropping with the approval of regorafenib in 2013. From 2013 through 2016, regorafenib was the dominant $3 \mathrm{~L}$ treatment.

Measuring the impact of survival due to later treatment lines, can be confounded by the small numbers of patients for any given treatment line, the number of different drugs used for these treatments and the impact of additional later treatments. To correct for this, we investigated the cumulative impact of drugs by looking at the time period when they were used and also measuring OS from a common time point: the start of 3L treatment.

We defined 3 patient cohorts, grouped by the year in which $3 \mathrm{~L}$ treatment began to match the major shifts in treatment patterns over time (Fig. 6a and Additional file 1: Table S5). The first group started 3L treatment between 2002 and 2006 (73 patients). The second group started 3L between 2007 and 2012 (198 patients) and the third group started 3L in 2013 or later (73 patients).

As shown in Fig. 6b in the 2002-2006 group, characterized by the dominant use of imatinib in 3L or later, the median OS from the start of 3L therapy was 12.8 months. Although imatinib was the dominant $3 \mathrm{~L}$ drug in this period, $52 \%$ of patients from this period received additional treatments beyond 3L (Table 1). In the 2007-2012 group characterized by the frequent use of nilotinib or sorafenib, the median OS was 22.4 months. In the $2013+$ group, characterized by the dominant use of $3 \mathrm{~L}+$ regorafenib, the median OS was 29.3 months.

\section{Factors affecting $3 \mathrm{~L}$ OS}

Using a Cox regression model, we investigated variables affecting OS as measured from the start of 3L treatment. Of the variables found to be significant in univariable 
analysis (Additional file 1: Table S6), only the time period $3 \mathrm{~L}$ treatment began lost significance in the initial multivariable analysis. Variables maintaining significance in the initial multi-variable analysis were: patient-reported progression in $2 \mathrm{~L}(p=0.001, \mathrm{HR} 1.698)$, patient treated with regorafenib at any time $(p<0.0001$, HR 0.441), age at start of treatment $(p<0.0001$, HR 1.020), gender ( $p=0.041$, HR 0.769, favoring OS in females) and whether or not the patient had a known mutation type ( $p=0.011$, HR 0.715, favoring known mutation). When we replaced the known/unknown variable with the actual mutation the results were similar (Additional file 1: Table S7) with the exception of gender and unknown mutation (as a category in the mutation variable) which both lost significance ( $p=0.14$ and $p=0.192)$.

These results suggest that the use of nilotinib and/or sorafenib in $3 \mathrm{~L}$ or $3 \mathrm{~L}+$ treatment lines improved survival over imatinib, and that the use of $3 \mathrm{~L}$ regorafenib was associated with improved OS compared with use of nilotinib and/or sorafenib.

\section{Exploratory analysis of treatment choice and performance status}

In some cases, poor performance status may affect treatment choice. For example, patients with poor performance status might choice imatinib therapy instead of sunitinib or regorafenib if they believed imatinib was more tolerable. If this was common, it might reduce both PFS (or srPFS in the case of the LRG registry) and OS of groups with more imatinib patients. The LRG registry does not track performance status or tumor burden.

To explore the relationship of treatment choice, performance status and OS we investigated imatinib use in three areas; the reason that patients stopped treatment in the previous treatment line, the percentage of patients starting 3L with imatinib compared to nilotinib or sorafenib and the survival of $3 \mathrm{~L}$ patients starting imatinib versus those starting $3 \mathrm{~L}$ nilotinib or sorafenib.

As our main comparison group, we used 3L treatments where patients started treatment between 2007 and 2012. We chose this group because it had the greatest heterogeneity in terms of both drug use and choice of treatment options available.

In the patients starting $3 \mathrm{~L}$ treatment between 2007 and 2012, patients without progression in $2 \mathrm{~L}$ treatment (no report of progression from an evaluation or as reason for stopping treatment) choose $3 \mathrm{~L}$ imatinib (compared to nilotinib and sorafenib) more often than patients reporting $2 \mathrm{~L}$ progression (51\% versus $24 \%$ ). In the 2007 and 2012 group, patients listing side effects as reason for stopping $2 \mathrm{~L}$ treatment choose $3 \mathrm{~L}$ imatinib (30\% of $3 \mathrm{~L}$ imatinib patients) more often than other drugs for $3 \mathrm{~L}$ treatment (13\% of nilotinib patients and $11 \%$ of sorafenib patients) and patients choosing 3L imatinib within the time frame of maximum choice (2007-2012) had equal survival to those choosing $3 \mathrm{~L}$ nilotinib/sorafenib $(p=0.527)$.

\section{Exploratory analysis of surgery}

Since it has been suggested that surgery for patients with metastatic GIST may be beneficial [34-36], we investigated the impact of surgery within $2 \mathrm{~L}$ and $3 \mathrm{~L}$ treatments. Given the limitations of retrospective data in evaluating surgical benefit (see Surgery and Surgery Limitations in the "Discussion" section), the first question that we were interested in was whether surgery was equally balanced in the different groups within our study. In $2 \mathrm{~L}$ treatment, surgery was well-balanced with $14.5 \%$ of sunitinib patients having surgery within $2 \mathrm{~L}$ and $9.5 \%$ of patients never receiving sunitinib having surgery. The percentage of patients have surgery in third line treatment was also well-balanced with respect to 3L treatment start date categories (2002-2006 12.3\%, 2007-2013 6.6\% and 2013+ $9.6 \%)$ and patients having $3 \mathrm{~L}$ regorafenib $(9.9 \%$ had surgery) or never having regorafenib (7.7\% had surgery).

Patients having surgery within both $2 \mathrm{~L}$ and $3 \mathrm{~L}$ had significantly better $2 \mathrm{~L}$ or $3 \mathrm{~L}$ OS than patients not having surgery within those treatment lines. The median OS in 2L was 66.1 months for patients having 2L surgery $(\mathrm{n}=81)$ versus 32.4 months for patients not having $2 \mathrm{~L}$ surgery $(\mathrm{n}=445) ; p=0.0008$, HR 0.56 CI $0.42-0.64)$. The median OS in 3L was 37.4 months for patients having 2L surgery $(\mathrm{n}=36)$ versus 19.7 months for patients not having $2 \mathrm{~L}$ surgery $(\mathrm{n}=308)[p=0.0008, \mathrm{HR} 0.40,95 \mathrm{CI}$ 0.25-0.75].

Patient-reported options for reporting the reason for surgery were: metastasis, primary tumor, primary tumor and metastasis, local recurrence and other. In patients reporting $2 \mathrm{~L}$ or $3 \mathrm{~L}$ surgery, only surgeries that involved a primary tumor (primary tumor or primary tumor with metastases) separated significantly from other reasons, however this type surgery was rare in $2 \mathrm{~L}(\mathrm{n}=9)$ and involved only 2 cases in $3 \mathrm{~L}$.

Interestingly, given the option to choose Clear Margins, No Clear Margins or Not Known, the No Clear Margins group had worse OS in both $2 \mathrm{~L}$ and $3 \mathrm{~L}$. For $2 \mathrm{~L}$ patients, the median OS was, Clear Margins $(n=23) 61.3$ months, No Clear Margins $(n=18) 21.4$ months and Not Known $(n=40) 63.4$ months. Compared to Clear Margins, the No Clear Margins patients had increased risk of death, HR 3.87 (CI 1.79-8.34), $p=0.0056$ ).

\section{Discussion}

Imatinib-resistant GIST remains challenging to treat. However, OS has improved significantly over time. This appears to be primarily due to increased access to new treatments; especially sunitinib and regorafenib, but also 
the frequent use of nilotinib and sorafenib in this patient population prior to regorafenib availability.

The very short PFS in patients receiving placebo in the randomized sunitinib [20] or regorafenib clinical studies [21] validates the long-standing hypothesis that stopping TKI treatment in the setting of TKI-resistant GIST results in rapid disease progression. In fact, a randomized study demonstrated that imatinib re-challenge of patients with imatinib- and sunitinib-resistant GIST improved PFS compared with placebo [37]. Therefore, use of TKIs such as nilotinib and sorafenib might act similarly; controlling imatinib-sensitive and some, but not necessarily all, imatinib and/or sunitinib resistant clones with secondary mutations, thus providing a benefit after imatinib/sunitinib failure.

The initial report [20] showed an OS benefit for sunitinib compared to placebo in a phase III clinical trial; however, in the final analysis in 2012 [38] there was no longer an OS benefit $(p=0.306)$. The high rate of cross-over from placebo to sunitinib obscures the survival benefit. It is not possible to determine the actual survival benefit with this trial design which is also the same design used in the GRID trial for regorafenib. The short time off of medication combined with the ability to access additional treatments obscures the actual benefit. Interestingly, patients in the LRG registry showed a similar pattern with respect to time on $2 \mathrm{~L}$ treatment. Patients starting 2L prior to 2006 initially had poorer survival than patients that started $2 \mathrm{~L} \geq 2006$ (Fig. 4), however the survival curves eventually cross after about 6 years. It's tempting to speculate that the long-term survivors might have similarities that allow patients in both groups to survive long-term in spite of different initial treatments. An example would be SDH-deficient patients which, in general, are known to have a more indolent course of disease [29].

Herein, we report a real-world estimate of median OS for $2 \mathrm{~L}$ sunitinib from the start of treatment of 32.3 months and a median srPFS of 8.4 months. Both of these survival estimates, especially OS, are longer than previous reports. PFS or Time to Progression (TTP) times reported by investigator assessment in clinical studies are often longer than those reported using blinded central radiology review (e.g. GRID [21]). Notably, our registry srPFS time reported here (8.4 months) is almost identical to the investigator reported TTP (8.3 months) in a very large (1124 patients) treatment use trial reported by Reichardt et al. [39].

We investigated the reasons for longer OS of the LRG registry patients receiving $2 \mathrm{~L}$ sunitinib and $3 \mathrm{~L}$ regorafenib compared to data from clinical studies and other reports. One significant finding is that OS has improved over time, so our registry population benefits from including patients from later time periods, especially compared to the time period when the phase III sunitinib trial was conducted. For example, if we compare the median OS for LRG patients starting 2L sunitinib prior to 2006 (Fig. 4) to the phase III clinical study which enrolled patients from December, 2003 until January, 2005, the median OS is much closer, 22.1 (LRG) vs 16.8 months (phase III study). Another factor is that a higher percentage of LRG patients starting $2 \mathrm{~L}$ did not have documented progression in $1 \mathrm{~L}$ compared to patients in the clinical studies. In our series, 374 of the 436 (86\%) of $2 \mathrm{~L}$ sunitinib-only patients reported progression with $1 \mathrm{~L}$ treatment. The OS from the start of $2 \mathrm{~L}$ between patients reporting progression in $1 \mathrm{~L}$ and patients not reporting progression in $1 \mathrm{~L}$ differed substantially, 30.8 months vs. 45.5 months respectively $(p=0.0055$, HR 1.597). In our regorafenib analyses, we focused on $3 \mathrm{~L}$ treatment; in the case of the GRID study, patients were not limited to 3L and 44\% of the regorafenib group (59 of 133) had > two lines of previous therapy. As expected, median OS decreases with each line of therapy.

An area of active investigation by our group is whether proactive, educated, engaged patients, such as those who are represented in the LRG registry, have better outcomes than less engaged patients. For example, registry patients may more frequently seek out additional treatments after failure of standard treatments, including clinical studies and off-label treatments. This hypothesis is supported by the high percentage of patients undergoing treatment beyond 3L. Patients in the LRG registry may more frequently consult with GIST experts; possibly resulting in greater access to additional therapies, including investigational agents.

In regard to the hypothesis that patients with poor performance status might choose imatinib in later treatment lines. We cannot exclude that this is the primary reason that some patients choose imatinib; however, our data suggests that the number choosing imatinib for this reason may be fairly small and may not significantly impact OS. In fact, using $3 \mathrm{~L}$ as an example, we found the opposite case was more likely with a higher percentage of $3 \mathrm{~L}$ patients not reporting progression in $2 \mathrm{~L}$ choosing imatinib (51\% of imatinib patients starting 3L between 2007 and 2012) compared to patients reporting progression in $2 \mathrm{~L}$ (24\% of $3 \mathrm{~L}$ patients staring between 2007 and 2012). It is likely that a factor other than drug choice is more indicative of patients with very poor performance status. This factor is how many patients successfully transition to the next treatment line. For patients in the LRG registry, about $30 \%$ (range $27.3-30.7 \%$ ) of patients fail to move to the next treatment line at each stage from the $2 \mathrm{~L}$ to $3 \mathrm{~L}$ transition until the $5 \mathrm{~L}$ to $6 \mathrm{~L}$ transition rising to about $50 \%$ at the $6 \mathrm{~L}$ to $7 \mathrm{~L}$ transition. The percentage of 
patients able to successfully transition to the next treatment line is related to both performance status (with the sickest patients unable to transition to the next treatment line) and availability/access to additional treatment options, which varied over time.

\section{Limitations}

Life Raft Group registry members are self-referred. Lowrisk patients are less likely to participate, and the LRG registry has a higher percentage of high-risk patients and patients with metastatic disease at diagnosis compared to population-based studies [1, 40]. Younger patients are more likely to be internet/technology savvy than older patients and thus more likely to participate in the registry. Proactive patients may also be more likely to participate in the registry as well as more likely to seek treatment from GIST expert centers and to participate in clinical trials. Lack of internet access, language barriers and social/economic status are also likely barriers to participation. In the vast majority of cases, patients reported as not knowing their mutation, did not have a mutational test performed. However, in some cases, it's possible that a mutational test was performed without the patient's knowledge or understanding of the test and it's also possible that some patients failed to report the test to the registry.

In our opinion, the patients in the second line comparison arms were more likely to be subject to selection bias compared to the third line patients. This is because sunitinib was generally available for almost all of the $2 \mathrm{~L}$ patients, but for $3 \mathrm{~L}$ patients, the treatments were largely selected by which treatment patients were able to access in different time periods. In some cases, there may have been reasons that a patient selected a drug other than sunitinib for $2 \mathrm{~L}$, for example, two patients with mutations known to be sunitinib-insensitive (D842V mutations) selecting crenolanib (a PDGFRA inhibitor with activity against the D842V mutation) instead of sunitinib for $2 \mathrm{~L}$. For this reason, the comparisons of other drugs compared to sunitinib in $2 \mathrm{~L}$ should be interpreted with caution. This selection bias is more likely to affect the comparison groups than the sunitinib groups.

Five and a half percent of registry patients had a combination treatment. Combination treatments were more common after second line, with $11.4 \%$ of patients receiving a combination treatment when treatment lines beyond $2 \mathrm{~L}$ were combined. In both $2 \mathrm{~L}$ and $3 \mathrm{~L}$, patients receiving a combination treatment did somewhat better than patients not receiving a combination, however the difference was not significant. To generate the most conservative estimate of benefit when comparing treatments, combination treatments were excluded from the sunitinib (2L) and regorafenib (3L) groups but included in their respective comparison groups. These comparison groups are essentially best alternative treatments (physician's choice) including combinations.

\section{Surgery and surgery limitations}

The limitations of retrospective data to evaluation surgical benefit for metastatic GIST have been well-described in the literature [34-36]. A primary concern is that healthier patients are often better surgical candidates. In addition to these well-described limitations, the data structure in the LRG registry was not designed to identify generalized progression versus local progression or stable metastatic disease at the time of surgery. Given these limitations, we can only state that patients that had surgery in $2 \mathrm{~L}$ or $3 \mathrm{~L}$ had longer $\mathrm{OS}$ than those that did not, but we cannot conclude whether this was due to surgical benefit or because they were healthier patients. Failure to obtain clear margins in $2 \mathrm{~L}$ or $3 \mathrm{~L}$ surgery was also associated with significantly worse OS. Since the term "clear margins" is more appropriately used to describe surgical margins after primary tumor therapy, it is necessary to consider how patients might interpret it in the context of $2 \mathrm{~L}$ or $3 \mathrm{~L}$ surgeries. In this context, it is more likely to be interpreted by patients and registrars as no evidence of disease after surgery. Interestingly, when given the choice of Clear Margins, Not Known or No Clear Margins, Clear Margins and Not Known grouped closer together (especially in 2L) and the No Clear Margins patients had clearly worse OS.

Given the limitations of retrospective surgery data, our primary concern was whether surgery might influence our primary medical treatment analysis if surgery was unbalanced across treatment groups. This did not appear to be the case. Also, given the limitations, we did not include surgery in the multi-variable analysis.

\section{Conclusions}

The real-world data reported here strongly support the hypothesis that sunitinib improves OS in advanced GIST patients. It also suggests that use of TKI's in the 3L, especially nilotinib and sorafenib improved OS in the period prior to regorafenib approval. Regorafenib use was common in the 2013+ period and was associated with significantly improved survival of patients compared to the time periods characterized by dominant $3 \mathrm{~L}$ imatinib use (2002-2006) or 3L+ use of nilotinib and/or sorafenib (2007-2012). In a multi-variable analysis of OS from start of $3 \mathrm{~L}$, patients that received regorafenib at any time had a $61 \%$ reduction in the risk of death compared to those that never had regorafenib at any time (Additional file 1: Table S7). Interestingly, using Cox regression analysis, we also show a positive impact on $2 \mathrm{~L}$ OS of a drug taken after $2 \mathrm{~L}$ (regorafenib), something that is not possible with 
traditional clinic trial designs. When citing or referring survival times, it's important to understand that survival may have changed over time and referencing older data may be misleading. This is especially important to keep in mind when talking to patients.

These data support current clinical guidelines for treatment of advanced disease. Our data also suggest that continued development of effective TKIs may further improve the treatment of advanced GIST. In addition, our data support the use of patient reported data in addressing outcome questions that cannot be addressed in single arm interventional studies or by randomized studies of investigational agents vs. placebo that incorporate a cross-over design.

\section{Additional file}

Additional file 1. Additional tables.

\begin{abstract}
Abbreviations
2L: 2nd line; 3L: 3rd line; FDA: Federal Drug Administration; GIST: gastrointestinal stromal tumors; HR: hazard ratio; ICC: interstitial cells of Cajal; IM: imatinib; IRB: Institutional Review Board; KIT/PDGFRA WT: wildtype for both KIT and PDGFRA genes; LRG: Life Raft Group; NI: nilotinib; OS: overall survival; Pt: patient; RE: regorafenib; SO: sorafenib; srPFS: self-reported progression-free survival; SU: sunitinib; TKI's: tyrosine kinase inhibitors; TL: treatment line; WT: wildtype.
\end{abstract}

\section{Authors' contributions}

JC: conceptualization, data curation, formal analysis, methodology, visualization and writing —original draft. YW: formal analysis, investigation, methodology, validation and writing — review and editing. DM: data curation, investigation, resources and writing - review and editing. NS: conceptualization, funding acquisition, project administration, supervision and writing — review and editing. $\mathrm{MH}$ : conceptualization, formal analysis, methodology, supervision, visualization and writing — review and editing. All authors read and approved the final manuscript.

\section{Author details}

${ }^{1}$ Life Raft Group, 155 Route 46 West, Suite 202, Wayne, NJ 07470, USA. ${ }^{2}$ Portland VA Health Care System and Knight Cancer Institute, Oregon Health \& Science University, Portland, OR, USA.

\section{Acknowledgements}

We thank the patients that contributed to the LRG registry making this research possible.

\section{Competing interests}

$\mathrm{MH}$ : Consulting (Novartis, Bayer, Deciphera Pharmaceuticals, Blueprint Medicines, Molecular MD); Research funding (Deciphera Pharmaceuticals, Blueprint Medicines); Equity interest (Molecular MD); Expert Testimony (Novartis); Patent (1 patent licensed to Novartis). All other authors declare that they have no competing interests.

\section{Availability of data and materials}

The datasets used and/or analyzed during the current study are available from the corresponding author on reasonable request.

\section{Consent for publication}

Not applicable.

\section{Ethics approval and consent to participate}

The LRG registry is approved by the Quorum Institutional Review Board (IRB) of Seattle, WA. Informed consent was obtained from patients or guardians in accordance with the IRB protocol.

\section{Funding}

This work was funded by The Life Raft Group.

\section{Publisher's Note}

Springer Nature remains neutral with regard to jurisdictional claims in published maps and institutional affiliations.

Received: 21 January 2019 Accepted: 29 March 2019

Published online: 02 April 2019

\section{References}

1. Nilsson B, Bumming P, Meis-Kindblom JM, Oden A, Dortok A, Gustavsson B, et al. Gastrointestinal stromal tumors: the incidence, prevalence, clinical course, and prognostication in the preimatinib mesylate era-a population-based study in western Sweden. Cancer. 2005;103:821-9.

2. Burkill GJC, Badran M, Al-Muderis O, Meirion-Thomas J, Judson IR, Fisher C, et al. Malignant gastrointestinal stromal tumor: distribution, imaging features, and pattern of metastatic spread. Radiology. 2003;226:527-32.

3. Corless CL, Fletcher JA, Heinrich MC. Biology of gastrointestinal stromal tumors. J Clin Oncol Off J Am Soc Clin Oncol. 2004;22(18):3813-25.

4. Demetri GD, von Mehren M, Blanke CD, Van den Abbeele AD, Eisenberg $B$, Roberts PJ, et al. Efficacy and safety of imatinib mesylate in advanced gastrointestinal stromal tumors. N Engl J Med. 2002;347:472-80.

5. van Oosterom AT, Judson I, Verweij J, Stroobants S, di Paola ED, Dimitrijevic S, et al. Safety and efficacy of imatinib (STI571) in metastatic gastrointestinal stromal tumours: a phase I study. Lancet. 2001;358(9291):1421-3.

6. Dagher R, Cohen M, Williams G, Rothmann M, Gobburu J, Robbie G, et al. Approval summary: imatinib mesylate in the treatment of metastatic and/or unresectable malignant gastrointestinal stromal tumors. Clin Cancer Res. 2002;8(10):3034-8.

7. Goodman VL, Rock EP, Dagher R, Ramchandani RP, Abraham S, Gobburu JVS, et al. Approval summary: sunitinib for the treatment of imatinib refractory or intolerant gastrointestinal stromal tumors and advanced renal cell carcinoma. Clin Cancer Res Off J Am Assoc Cancer Res. 2007;13(5):1367-73.

8. Research AA for C. FDA approves stivarga for GIST. Cancer Discov. 2013;3(4):OF1.

9. von Mehren M, Randall RL, Benjamin RS, Boles S, Bui MM, Casper ES, et al. Gastrointestinal stromal tumors, version 2.2014. J Natl Compr Cancer Netw JNCCN. 2014;12(6):853-62.

10. Corless CL. PDGFRA mutations in gastrointestinal stromal tumors: frequency, spectrum and in vitro sensitivity to imatinib. J Clin Oncol. 2005;23:5357-64.

11. Hirota S, Isozaki K, Moriyama Y, Hashimoto K, Nishida T, Ishiguro S, et al. Gain-of-function mutations of c-kit in human gastrointestinal stromal tumors. Science. 1998;279(5350):577-80.

12. Heinrich MC, Corless CL, Blanke CD, Demetri GD, Joensuu H, Roberts PJ, et al. Molecular correlates of imatinib resistance in gastrointestinal stromal tumors. J Clin Oncol Off J Am Soc Clin Oncol. 2006;24(29):4764-74.

13. Heinrich MC, Maki RG, Corless CL, Antonescu CR, Harlow A, Griffith D, et al. Primary and secondary kinase genotypes correlate with the biological and clinical activity of sunitinib in imatinib-resistant gastrointestinal stromal tumor. J Clin Oncol. 2008;26(33):5352-9.

14. Corless CL, Barnett CM, Heinrich MC. Gastrointestinal stromal tumours: origin and molecular oncology. Nat Rev Cancer. 2011. http://www.ncbi. nlm.nih.gov/pubmed/22089421. Accessed 18 Nov 2011.

15. Call J, Walentas C, Eickhoff J, Scherzer N. Survival of gastrointestinal stromal tumor patients in the imatinib era: life raft group observational registry. BMC Cancer. 2012;12(1):90.

16. Ng EH, Pollock RE, Munsell MF, Atkinson EN, Romsdahl MM. Prognostic factors influencing survival in gastrointestinal leiomyosarcomas implications for surgical management and staging. Ann Surg. 1992;215:68-77. 
17. (MetaGIST) GSTM-AG. Comparison of two doses of imatinib for the treatment of unresectable or metastatic gastrointestinal stromal tumors: a meta-analysis of 1,640 patients. J Clin Oncol. 2010;28:1247-53.

18. van der Graaf WTA, Tielen R, Bonenkamp JJ, Lemmens V, Verhoeven RHA, de Wilt JHW. Nationwide trends in the incidence and outcome of patients with gastrointestinal stromal tumour in the imatinib era. BJS. 2018;105(8):1020-7.

19. Joensuu H, Eriksson M, Sundby Hall K, Hartmann JT, Pink D, Scuhtte J, et al. One vs three years of adjuvant imatinib for operable gastrointestinal stromal tumor a randomized trial. JAMA. 2012;307:1265-72.

20. Demetri G, Vanoosterom A, Garrett C, Blackstein M, Shah M, Verweij J, et al. Efficacy and safety of sunitinib in patients with advanced gastrointestinal stromal tumour after failure of imatinib: a randomised controlled trial. Lancet. 2006;368(9544):1329-38.

21. Demetri GD, Reichardt P, Kang Y-K, Blay J-Y, Rutkowski P, Gelderblom $H$, et al. Efficacy and safety of regorafenib for advanced gastrointestinal stromal tumours after failure of imatinib and sunitinib (GRID): an international, multicentre, randomised, placebo-controlled, phase 3 trial. Lancet. 2012. http://www.thelancet.com/journals/lancet/article/PIISO 140-6736(12)61857-1/abstract. Accessed 26 Nov 2012.

22. Demetri GD, Reichardt P, Kang Y-K, Blay J-Y, Joensuu H, Schaefer K, et al. Final overall survival (OS) analysis with modeling of crossover impact in the phase III GRID trial of regorafenib vs placebo in advanced gastrointestinal stromal tumors (GIST). J Clin Oncol. 2016;34(4_suppl):156.

23. George S, Wang Q, Heinrich MC, Corless CL, Zhu M, Butrynski JE, et al. Efficacy and safety of regorafenib in patients with metastatic and/or unresectable Gl stromal tumor after failure of imatinib and sunitinib: a multicenter phase II trial. J Clin Oncol. 2012;30(19):2401-7.

24. Ben-Ami E, Barysauskas CM, von Mehren M, Heinrich MC, Corless CL, Butrynski JE, et al. Long-term follow-up results of the multicenter phase II trial of regorafenib in patients with metastatic and/or unresectable Gl stromal tumor after failure of standard tyrosine kinase inhibitor therapy. Ann Oncol. 2016;27(9):1794-9.

25. Dewaele B, Wasag B, Cools J, Sciot R, Prenen H, Vandenberghe P, et al. Activity of dasatinib, a dual SRC/ABL kinase inhibitor, and IPI-504, a Heat shock protein 90 inhibitor, against gastrointestinal stromal tumor-associated PDGFRAD842V mutation. Clin Cancer Res. 2008;14(18):5749-58.

26. Heinrich MC, Griffith DJ, McKinley A, Patterson J, Presnell A, Ramachandran A, et al. Crenolanib inhibits the drug-resistant PDGFRA D842V mutation associated with imatinib-resistant gastrointestinal stromal tumors. Clin Cancer Res. 2012. http://clincancerres.aacrjournals.org/content/early /2012/06/27/1078-0432.CCR-12-0625. Accessed 28 June 2012.

27. Evans EK, Gardino AK, Kim JL, Hodous BL, Shutes A, Davis A, et al. A precision therapy against cancers driven by KIT/PDGFRA mutations. Sci Transl Med. 2017;9(414):eaao1690.

28. Pender A, Jones RL. Olaratumab: a platelet-derived growth factor receptor-a-blocking antibody for the treatment of soft tissue sarcoma. Clin Pharmacol Adv Appl. 2017;4(9):159-64.

29. Weldon CB, Madenci AL, Boikos SA, Janeway KA, George S, von Mehren $M$, et al. Surgical management of wild-type gastrointestinal stromal tumors: a report from the National Institutes of Health Pediatric and Wildtype GIST Clinic. J Clin Oncol. 2017;35(5):523-8.

30. Cauchi C, Somaiah N, Engstrom PF, Litwin S, Lopez M, Lee J, et al. Evaluation of nilotinib in advanced GIST previously treated with imatinib and sunitinib. Cancer Chemother Pharmacol. 2011. http://www.ncbi.nlm.nih. gov/pubmed/22119758. Accessed 29 Nov 2011.

31. Montemurro M, Gelderblom H, Bitz U, Schütte J, Blay JY, Joensuu H, et al. Sorafenib as third- or fourth-line treatment of advanced gastrointestinal stromal tumour and pretreatment including both imatinib and sunitinib, and nilotinib: a retrospective analysis. Eur J Cancer Oxf Engl. 2013;49(5):1027-31.

32. Park SH, Ryu MH, Ryoo BY, Im SA, Kwon HC, Lee SS, et al. Sorafenib in patients with metastatic gastrointestinal stromal tumors who failed two or more prior tyrosine kinase inhibitors: a phase II study of Korean gastrointestinal stromal tumors study group. Invest New Drugs. 2012;30(6):2377-83.

33. Sawaki A, Nishida T, Doi T, Yamada Y, Komatsu Y, Kanda T, et al. Phase 2 study of nilotinib as third-line therapy for patients with gastrointestinal stromal tumor. Cancer. 2011;117(20):4633-41.

34. Raut CP, Posner M, Desai J, Morgan JA, George S, Zahrieh D, et al. Surgical management of advanced gastrointestinal stromal tumors after treatment with targeted systemic therapy using kinase inhibitors. J Clin Oncol. 2006;24(15):2325-31

35. DeMatteo RP, Maki RG, Singer S, Gonen M, Brennan MF, Antonescu CR. Results of tyrosine kinase inhibitor therapy followed by surgical resection for metastatic gastrointestinal stromal tumor. Ann Surg. 2007;245(3):347-52

36. Yeh C-N, Wang S-Y, Tsai C-Y, Chen Y-Y, Liu C-T, Chiang K-C, et al. Surgical management of patients with progressing metastatic gastrointestinal stromal tumors receiving sunitinib treatment: a prospective cohort study. Int J Surg Lond Engl. 2017:39:30-6.

37. Kang Y-K, Ryu M-H, Yoo C, Ryoo B-Y, Kim HJ, Lee JJ, et al. Resumption of imatinib to control metastatic or unresectable gastrointestinal stromal tumours after failure of imatinib and sunitinib (RIGHT): a randomised, placebo-controlled, phase 3 trial. Lancet Oncol. 2013;14:1175-82.

38. Demetri GD, Garrett CR, Schöffski P, Shah MH, Verweij J, Leyvraz S, et al. Complete longitudinal analyses of the randomized, placebo-controlled, phase III trial of sunitinib in patients with gastrointestinal stromal tumor following imatinib failure. Clin Cancer Res Off J Am Assoc Cancer Res. 2012;18(11):3170-9.

39. Reichardt P, Kang Y-K, Rutkowski P, Schuette J, Rosen LS, Seddon B, et al. Clinical outcomes of patients with advanced gastrointestinal stromal tumors: safety and efficacy in a worldwide treatment-use trial of sunitinib. Cancer. 2015;121(9):1405-13.

40. Cassier PA, Ducimetiere F, Lurkin A, Ranchere-Vince D, Scoazec J-Y, Bringuier P-P, et al. A prospective epidemiological study of new incident GISTs during two consecutive years in Rhone Alpes region: incidence and molecular distribution of GIST in a European region. Br J Cancer. 2010;103(2):165-70.

\footnotetext{
Ready to submit your research? Choose BMC and benefit from:

- fast, convenient online submission

- thorough peer review by experienced researchers in your field

- rapid publication on acceptance

- support for research data, including large and complex data types

- gold Open Access which fosters wider collaboration and increased citations

- maximum visibility for your research: over $100 \mathrm{M}$ website views per year
}

At BMC, research is always in progress.

Learn more biomedcentral.com/submissions 